\title{
Enhancing Food Security Through Innovation Platforms: Experiences from Research into Use Project in Rwanda
}

\section{Dusengemungu ${ }^{1}$, P. Kibwika ${ }^{2}$, FB Kiazze ${ }^{3}$}

${ }^{1}$ Researcher, Rwanda Agricultural Board, RWANDA

${ }^{2,3}$ Lecturers, Faculty of Agriculture, Makerere University, UGANDA

\begin{abstract}
Maize is an important food security crop in Rwanda and the East African region, however the maize value chain is not well developed and the productivity is still low partly because of low technology uptake by the smallholder farmers. Since 2006, the Department for International Development (DFID) supported the "Research Into Use" (RIU) programme in Rwanda to enhance the uptake of agricultural technologies using innovation platforms (IPs). Maize was one of the target crops for intensification particularly in Nyagatare District for which an IP was established. The purpose of the innovation platforms was to faciliate interaction of the key actors in the value chain including farmers, cooperatives, inputs suppliers, processors, traders, credits providers, local leaders, research and extension to establish mutual relationships for value chain development. This study assessed processes of establishing IPs and requirements for their effective operations and sustainability. Data were collected using focus group discussions, observations and interviews. SPSS and SNA softwares were used to analyze data. Through actor interactions in IPs, farmers` problems were prioritized by research; relationships were established between research institutions, NGOs, processors and finance institutions for value addition of maize thereby creating a pull effect for increased production and income. Increased production, productivity and incomes are core to food security. The IP was a mechanism for developing value chains that provided incentives and means for access to and adoption of technologies for increasing productivity of maize. Hower, functional IPs requires facilitation and capacity building of the actors to interact in a mutually beneficial manner.
\end{abstract}

Key words: Innovation, Innovation platform, Food security

JEL Classification Code: 031

\section{INTRODUCTION}

Despite the research successes registered in several agricultural projects implemented so far to improve food security, income, and nutrition, poverty is yet to be significantly reduced, It is hypothesized that the nature of linear research approach in addressing the interlinked productivity, natural resource management, market and policy challenges in isolation is one of 
the most critical causes underlying the agricultural under-performance (Roling, 2009). A new paradigm in agricultural research, technology, innovation and knowledge system is required to break the paradox, steer and accelerate the targeted agricultural development. Innovation platform is a new approach that holds promises to reverse the trend and enhance farmers' livelihoods and food security (Burchara et al., 2008). Several innovations platforms exist in different domains: ICT, construction, vehicles production and commercialization and agricultural commodities (Lundvall, 1992). Hall et al. (2001) have done a lot to explain agricultural innovation systems. They argue that agricultural innovation system framework stresses the importance of including all stakeholders and making organizations and policies sensitive to stakeholder agendas and demands. The approach builds on previous approaches such as Integrated Watershed Management and addresses productivity, market, natural resource management and policy and their interface issues.

On the basis of the above scenario, since 2006, the Department for International Development (DFID) in the United Kingdom (UK) has been supporting a program to enhance the uptake of relevant agricultural technologies through a project known as "Research Into Use" (RIU).

RIU currently operates in 12 of the poorest countries of Africa and Asia. The African countries include Zambia, Malawi, Nigeria, Sierra-Leone, Tanzania and Rwanda while the Asian countries are Bangladesh, Cambodia, India, Nepal, Pakistan and Vietnam. In implementing the project, RIU established innovation coalitions and innovation platforms in all those countries (RIU, 2010). The RIU project promotes uptake of relevant technologies to poor farmer and among these are; policies and processes directed towards crop science, forestry, fisheries management, livestock production and animal health, crop post-harvest technology and natural resource management.

Since 2008, this project has initiated four local agricultural Innovations Platforms (IPs) to promote technology diffusion in Rwanda. These IPs were formed, in different districts of Rwanda, namely Gatsibo for cassava, Gicumbi for irish potato, Nyagatare for maize and Karongi for farmers associations. According to RIU, an agricultural Innovation Platform is a platform specific to agriculture. It has a wider spectrum of actors and refers to any network of various actors developed in the agricultural sector and related activities (RIU, 2007). It may include providers of agriculture knowledge (research and extension), private sector, farmer's organizations, individuals' producers, local leaders, media, etc. working together for agriculture development. Agricultural platforms are set-up for reflection, analysis and learning about promoting innovations in agriculture (Sanginga et al., 2009). This research highlights key results in the "the Maize Innovation platform in Nyagatare district".

\section{MetHodology}

The study focussed on the maize innovation platform in Nyagatare District, Eastern province of Rwanda. Out of the literature review, the methodology included one focus group discussion (FDG) with a total of 12 key informants, participant observations and individual interviews with 30 actors from 55 members of the maize IP. Purposive sampling was used to select the FGD participants. They were purposively selected because they possessed vast information about the history, current functioning, opportunities and challenges of the platform. Those participants included representatives of actors as well as maize IP committee members. The FGD was moderated by the researcher while a reporter recorded notes to make sure that all participants' views were captured. In addition, a tape-recorder was also used to back-up the written notes.

Also, the participant observations were used to validate and or complement some of the information generated in the FGDs. The researcher observed the physical setting and environmental factors within which the maize IP's activities took place; such as existing 
initiatives, local infrastructure and local partners. This required the researcher to participate in the IP planned activities supported by RIU, such as workshops, field visits or learning events on farming techniques. Researcher observations generated insight and better understanding of the context and activities implemented by the IPs. The observation guide included details on the location of the IP, the office, the key players, the committee composition and the IP facilitators, attendance and participation of members, the incentives received from RIU, the local initiatives and partners, the challenges faced during the process and coping mechanisms. Also, the IP documents like MoUs, action plans were visualized and consulted. The information generated from observations and focus group discussions guided the design of individual interviews.

The interviews were administered face to face to the different categories of actors from the maize IPs. Two versions of the interview schedule were developed, one targeting farmers (70\% of the membership) and the other customized to the rest of the actors. The random sampling technique was used to select the respondents for the individual interviews. All questionnaires used were pre-coded and pre-tested before data collection. However, the respondents in pre-test were excluded in the sample for the survey.

At the end of the research, a feed-back workshop was convened and supported by RIURwanda Project to provide feed-back from the researcher about the main findings. This feed-back workshop helped to validate the findings of the research. Recording and analysis of quantitative data was done using SPSS software. Social Network Analysis (SNA) tools were also used to highlight the relationships between the IP actors.

\section{RESULTS AND DISCUSSIONS}

This section discusses the main results which include the maize IP modus operandi, the membership and representation, the Memorandum of Understanding, the activities planned, the achievements so far, the challenges and future plans.

\section{Modus operandi}

The maize platform was initiated in 2008 by the Research Into Use programme, in partnership with the Ministry of Agriculture (MINAGRI) and the Rwanda Development Organisation (RDO), a non-government organisation (NGO). This platform was constituted by a cluster of eleven public and private organisations engaged in maizerelated activities. Prior to the beginning of the platform activities, the RIU programme supported several sensitisation meetings to map out the stakeholder groups, and solicited their commitment to the platform activities. The process was participatory and inclusive, involving; farmers, local leaders, researches, extensionists, NGOs, and traders in the planning of platform activities.

\section{Members and representation}

The maize innovation platform started with 55 members, the majority (70\%) being farmers. For governance of the platform, a committee of six members was set-up. The committee comprised of a president (farmer), a vice/president (farmer), a secretary (local leader), a treasurer (an NGO extension worker), two counsellors (one researcher and one farmer). Representation of stakeholders on the maize platform committee was determined by the number of members from the stakeholder categories. This implied that farmers who were the majority also took on more positions in the committee composition. The traders for example were not represented on the innovation platform committee because they were only a few. 


\section{Signing of Memorandums of Understanding}

At the time, there was no experience of such diverse actors along the value chain working together to promote a commodity like maize and its related products. Setting up such an arrangement therefore required a lot of preparatory planning. For this reason, the RIU programme took four months (May 2008-August 2008) to carry out pre-planning activities and the actual implementation of the platform activities started in late 2008. During the preplanning activities, the programme staff found it necessary to develop binding mechanisms in the form of Memorandum of Understanding (MoU) for platform members and local organisations. Three types of Memorandums were signed. The first Memorandum was among the platform members regarding sharing of roles and responsibilities. The second one was between the Research Into Use programme and the platforms, and the third was between the programme and local NGOs. Development of these Memorandums allowed for the stakeholders to negotiate their interests in a transparent manner, to establish common understanding of the intentions of the platform, developing trust amongst themselves, and to develop a shared vision. The purpose of the memorandums was to clarify the roles and responsibilities of the partners and ensure their commitment to undertake their obligations. The Memorandums of Understanding were signed in March 2010 although they should have been signed in March 2009, according to the plan. This delay was attributed to the complex process of negotiation of interests which is often under-estimated both in terms of process and time. Some stakeholders needed to consult their constituents and also seek advice of lawyers before they could sign the Memorandums.

\section{Activities}

The most critical constraints identified by the maize innovation platforms included lack of good quality seeds and predominant use of poor crop management techniques. Since these were seen to be the factors that most limited agricultural production and farmer income they formed the core of issues to be addressed, at least at the beginning. At this stage, the convergence of interests began to appear. The table below summarises the major activities of the different stakeholder groups.

Table 1 Activity schedules and responsible stakeholder groups in maize platform, Nyagatare District

\begin{tabular}{|c|c|c|}
\hline Activities & Responsible & Timeline \\
\hline Land consolidation & Farmers and local leaders & $\begin{array}{l}\text { June-August } \\
2008\end{array}$ \\
\hline $\begin{array}{l}\text { Trainings through farmer field schools and } \\
\text { study tours organized on maize production }\end{array}$ & $\begin{array}{c}\text { RIU, Researchers, } \\
\text { extensionists and NGOs }\end{array}$ & $\begin{array}{l}\text { July } \\
2008\end{array}$ \\
\hline Use of oxen for ploughing & $\begin{array}{l}\text { Farmers and progressive } \\
\text { farmers and NGO }\end{array}$ & August 2008 \\
\hline $\begin{array}{l}\text { Purchase of agricultural inputs including } \\
\text { inorganic and organic fertilizers / inorganic }\end{array}$ & RIU, IP committee and NGOs & August 2008 \\
\hline $\begin{array}{l}\text { Planting improvedi varieties of maize and } \\
\text { use of appropriate agronomic practices }\end{array}$ & $\begin{array}{l}\text { Farmers, Researchers, } \\
\text { extensionists and NGOs }\end{array}$ & $\begin{array}{l}\text { September 2008, } \\
\text { first planting } \\
\text { season for the } \\
\text { Maize IP }\end{array}$ \\
\hline $\begin{array}{l}\text { Promoting improved post harvest handling } \\
\text { through the purchase of small shelling } \\
\text { machines. }\end{array}$ & Traders and farmers & December 2008 \\
\hline $\begin{array}{l}\text { MoU development and sharing of } \\
\text { responsibilities }\end{array}$ & All actors involved & March 2009 \\
\hline
\end{tabular}




\begin{tabular}{|c|c|c|}
\hline Construction of maize driers & $\begin{array}{c}\text { Farmers, IP committee and } \\
\text { RIU }\end{array}$ & June 2009 \\
\hline $\begin{array}{c}\text { Establishment of the Maize investment } \\
\text { group (NYAMIG) }\end{array}$ & All stakeholders and RIU & August 2009 \\
\hline $\begin{array}{c}\text { Increased access to credit through dialogue } \\
\text { with financial institution to improve } \\
\text { agricultural financing. }\end{array}$ & RIU and Financial Institutions & December 2009 \\
\hline
\end{tabular}

Stakeholder agreement on sharing roles as indicated in this table is usually more easily stated on paper than in reality. It takes commitment for the platform members to undertake their assigned roles with determination. Motivation to undertake these roles and actively participate relies largely on each of the platform member's expectations. The articulation of the above-mentioned constraints was possibly the major driver for farmers to join the maize platform. Farmers expected to further increase their production and sub sequent income if they were able to access better quality seed and improved farming practices. As a result of addressing the constraints and developing increased production, traders and processors also expected to increase their volume of business - hence profits. The NGOs, researchers and Government agents also expected to increase their efficiency by working with organised and motivated clients.

\section{Achievements}

Increased access to and use of improved and good quality maize: Quality Protein Maize (QPM) varieties were introduced through the platform. This variety is dual purpose: it gives better yields than other open-pollinated maize varieties, and also has a high protein content which is crucial for the improvement of nutrition. Increased yield of the maize crop from 0.5 tonnes per hectare before RIU interventions to about 6 tonnes per hectare currently has also led to the introduction of other support technologies such as maize driers to enhance value addition.

Increased knowledge and skills in using improved maize production technologies: The maize platform adopted a Farmer Field School approach to farmer learning. Specifically, some of the knowledge and skills gained from the Farmer Field School training and Study tours were related to selection of good planting material/seed, spacing and planting, disease and pest management, and fertiliser application. For example, a study tour to Uganda by Rwandan maize farmers stimulated them to take on several initiatives among which is acquiring small machines for milling maize to add value. As one farmer put it: "Akanyonikatagurutse ntikamenya iyo bweze" which means: "A bird which doesn't fly can't know where food can be found". This was an expression of the farmer benefits from tours with regard to accessing relevant information and technologies.

Strengthening social networks and farmers' organisations: The maize innovation platform strengthened collaborative relationships between various stakeholders in a local maize value chain, namely: farmers and farmer co-operatives, researchers and extensionists, processors and input suppliers, financial service providers, local leaders and policy makers as shown by the figure 1 . 


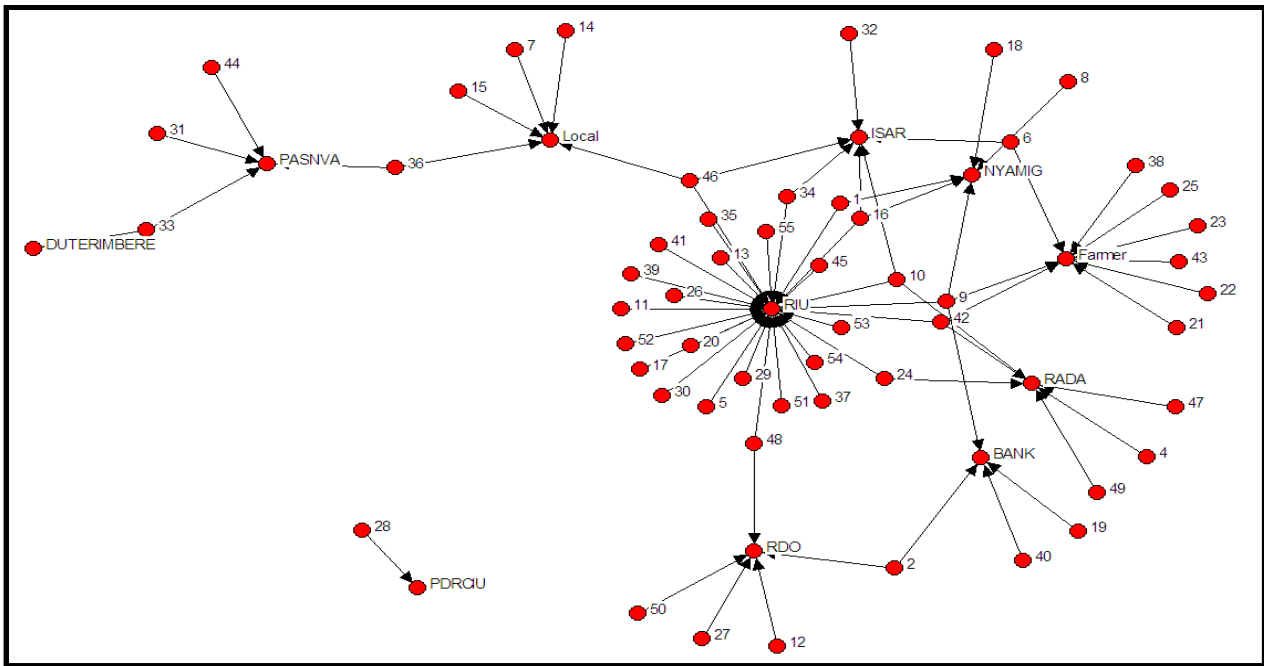

Figure 1: Maize IP social network (55 members)

Source: Dusengemungu L. 2010, findings using Social Network Analysis (SNA) Software.

The social networks of all the stakeholders involved was widened and further strengthened their mutual trust. For example, interaction among farmers resulted in seed exchanges and field visits among farmers to share knowledge and experiences. Creation of new business deals for platform members: The maize platform has given birth to maize investment group "Nyagatare Maize Investimenet Group" (NYAMIG) as the business arm of the innovation platform. NYAMIG is made up of about 30 farmers' associations. It is responsible for searching for markets and marketing maize on behalf of the maize platform. Through this, the platform has now established a voucher system, that enables farmers to get warrants (vouchers) so that they can safely store their produce for longer periods to access better market prices and avoid exploitation by maize traders. The voucher programme in itself serves as collateral for the farmers to access bank loans and at the same time make business deals with input dealers to purchase seed and fertilisers.

Access to new maize markets: New markets for maize were accessed by farmers in Kigali (the capital of Rwanda) and other urban centres. World Food Programme is currently buying the maize flour distributed to refugee camps in the country. This was an opportunity for farmers to increase their profits and overall benefits from their efforts. In a study on diffusion of innovations, Cochrane (as cited in Sanginga et al., 2009), clearly emphasised that the windfall profit for early adopters is the foremost incentive. The amount of cash in farmers' pockets and the change in the household livelihood motivate not only the producers but also all their neighbours. For example, one maize farmer in Nyagatare District, proudly asserted during a training session that: "From the past two maize seasons, I was able to buy two motorcycles, build a new house and I am planning to acquire a computer for my children to use". Despite the fact that the farmer had been growing maize for many years, he had never achieved such tangible benefits by doing things differently, using improved seeds and fertilisers. In addition, the Research Into Use programme facilitated the establishment of linking the farmers' association (NYAMIG) with the World Food Programme, thereby providing new market opportunities. 


\section{Challenges}

The maize innovation platform had a diversity of stakeholders whose expectations and needs differed. The management and co-ordination of platform activities, as well as capacity building for the different stakeholder groups in such a short time pose a major challenge. This resulted in discontent among some platform members who felt that their needs were not given as much priority as those of their counterparts. A sense of dissatisfaction affects the commitment and ownership of the innovation platform initiative. The pre-planning activities for establishing the maize platform took a very long time and were expensive. The funds were provided by the Research Into Use programme but otherwise it turned out to be an expensive process. The platform members thought that some of those funds would have been better spent on implementing platform activities rather than some of the pre-planning activities. While it is desirable to maintain the memberships and stakeholder composition of the platforms, the membership of the maize innovation platform is very dynamic, with new members joining and others dropping out. This in itself is a challenge because the platform is constantly changing its membership, which may imply continuous changes in roles and responsibilities. An attitude of dependency associated with development projects is a constraint to empowerment and self-reliance. This attitude can develop over time as projects tend to provide hand-outs and inducements for people to participate. The platform struggled to convince people that they will be rewarded by their acts and that they should not expect immediate rewards like cash incentives (from the Research Into Use programme). It was thought that acquisition of skills would be a strong incentive but it turned out that this was not the case for many platform members especially for the processors and traders. The Rwandan government already had a policy of rewarding hard-working and innovative farmers with items such as wheelbarrows, shovels, spades, etc., but the cash incentive was stronger. These kinds of incentives were expected by many platform members. An incentive scheme is to be elaborated for members to maintain the membership.

\section{Future plans}

The maize innovation platform is considered to have been successful and has been tasked in taking the lead in establishing maize innovation centres in all the distict areas. It is anticipated that these centres will serve as learning sites in the process of scaling out products of the platform through demonstrations, and at the same time provide space for the farmers to interact and share lessons. The centres could develop into new platforms. Continuity of the platform activities will most likely be affected when its RIU programme funding stops. This may slow down activities if alternative funding is not found in time and if partners do not demonstrate commitment, including co-funding. The success of the process of implementation is largely dependent on the Ministry of Agriculture and other development partners taking ownership of the platform and commitment to support institutionalisation in other (national) organisations or programmes. At the same time, however, the Research Into Use programme has developed a strategy for putting the responsibility of the platform in the hands of public-private partners for for funding the maize innovation centres in all district areas. This is very important for the continuity of this excellent experience. This step could furthermore contribute to local ownership. Several partners, including NGOs and government parastatals, could support the work and/or champion the activities of the maize platform after the programme phases out support. This requires mobilisation of local organisations including farmers' organisations, research institutes, extension organisations, NGOs and development partners. The operation of the innovation platform turned out to be an effective approach in promoting the development of a commodity-based agricultural value-chain. This is carried out in a holistic manner as it creates space for participation and brings together a wide range of stakeholders to work together towards a common goal. In doing so, social networks are built and strengthened, and the stakeholders become empowered to negotiate, lobby for and demand what they need from public and private service providers. There must be a local facilitator (a local NGO or government ministry) that takes on the role of driving platform activities after the donor ceases to fund platform activities. Local ownership is critical to support the work or take the lead after phasing out support of a donor. 


\section{CONCLUSIONS AND RECOMMENDATIONS}

The necessary negotiations and other pre-planning activities make the establishment of a platform a long and costly process. Establishing an innovation platform requires the participation of a wide range of stakeholders from the private as well as the public sector, but also their commitment to actively participate. The diversity of interests of the various stakeholders could be a constraint, and convergence of interests needs to be achieved. Only when there is convergence of interests and commitment, are members likely to collaborate fruitfully. Capacity building for all stakeholder members is a critical element in developing platforms. The Research Into Use programme however emphasises building the capacity of the demand side (farmers) to participate in innovation platforms and probably over-estimated the capacity of other platform members. To comprehensively develop capacity of actors, a thorough capacity needs assessment is required. One of the flaws of this programme has been that it started without such a needs assessment. The strongest incentives to the platform members are those that have economic value. It is therefore important that the platform members specify their anticipated economic expectations prior to joining the platform. Support services to the innovation platform, such as training, should then be geared towards unleashing the economic benefits to the platform members; otherwise, training per se may not be valued very much as an incentive. Memorandums of Understanding as an instrument for operationalisation of innovation platforms is a good starting point for clarifying the roles of platform members and to get their commitment on performing their roles. But the memorandums turned out to by themselves not be adequate for inspiring platform members to perform their expected roles. Capacity building is essential for the various stakeholders to realise the potential opportunities in the platforms, to motivate them to continue engaging. However, the operationalisation of the IPs require establishment of functional and strong linkages where farmers' interests, needs and/or opportunities are core to the other participating actors in the forum. Public-private partnership is paramount for surtainability issues.

\section{References}

Burchara, R., Tenywa, M., Majaliwa,J.G.M.,Chirius, W., Mugabo, J.,Nyamwaro,S.O. Adewale A. (2008) Integrated Agricultural Research for Development (IAR4D) an Approach to Enhance Small-holder Farmers' Livelihood:Experiences from Lake Kivu Region, FARA, Accra

Hakizimana, P. (2007). Rwanda agricultural extension services system: Operation and funding modalities. Paper presented at UN-ECA EA-SRO, 11th Session of Intergovernmental Committee of Experts (ICE) Meeting, Bujumbura, Burundi, from 16 to 19 April 2007.

Hall, A.J., Sivamohan, M.V.K., Clark, N.G., Taylor, S. and Bockett, G. (2001). Why research partnerships really matter: innovation theory, institutional arrangements and implications for developing new technology for the poor. World Development 29(5): 783-797.

Lundvall, 1992). Lundvall, B.A. (ed.). (1992). National Systems of Innovation and Interactive Learning. London, UK: Pinter.

RIU. (2010). Putting Research into use: stimulating demand in Sub-Saharan Africa, Retrieved, March 24, 2010 from www.researchintouse.com

Sanginga, P.C., A. Waters-Bayer, S. Kaaria, J. Njuk and C. Wettasinha (2009). Innovation Africa: enriching farmers' livelihoods. Earthscan, UK.

Roling, N. (2009). Conceptual and methodological developments in innovation in Innovation Africa: Enhancing farmers'Livelihoods, Earthscan in the UK and USA, pp 9-34.

Dusengemungu L. June 2010, Capacity for sustaining agricultural innovation platforms in Rwanda, case study of "Research Into Use" Project, Makerere University, Thesis for a Master's degree in Agriculture Extension/Education, published by Lambert Academic Publishing, Saarbrucken, Germany. pp 115. ISBN: 978-3-8484-9631-0. 